\title{
Development of Performance Models for Boiler Feed Water Treatment Ion Exchange Facility
}

\author{
Kenneth Kekpugile Dagde \\ Department of Chemical, Petrochemical Engineering Rivers State University, Port Harcourt, Nigeria \\ Email: dagde.kenneth@ust.edu.ng
}

How to cite this paper: Dagde, K.K. (2018) Development of Performance Models for Boiler Feed Water Treatment Ion Exchange Facility. Advances in Chemical Engineering and Science, 8, 280-297.

https://doi.org/10.4236/aces.2018.84020

Received: April 18, 2018

Accepted: October 23, 2018

Published: October 26, 2018

Copyright $\odot 2018$ by author and Scientific Research Publishing Inc. This work is licensed under the Creative Commons Attribution International License (CC BY 4.0).

http://creativecommons.org/licenses/by/4.0/

(c) (i) Open Access

\begin{abstract}
The treatments of raw water using resins embedded with cation and anion were investigated in this study via a developed mathematical model. The developed mathematical model was used to predict the amount of sodium $\left(\mathrm{Na}^{+}\right)$, calcium $\left(\mathrm{Ca}^{2+}\right)$, magnesium $\left(\mathrm{Mg}^{2+}\right)$ and ammonium $\left(\mathrm{NH}_{4}^{+}\right)$ions removed by the resin embedded with hydrogen ion $\left(\mathrm{H}^{+}\right)$in the cation bed. The model was also used to investigate the amount of chloride $\left(\mathrm{Cl}^{-}\right)$and sulphate $\left(\mathrm{SO}_{4}^{2-}\right)$ ions treated by the resin embedded with hydroxyl ion $\left(\mathrm{OH}^{-}\right)$in the anion bed. The effect of flow rate and superficial velocity were also investigated. The simulation results showed that there was significant reduction of $\mathrm{Na}^{+}, \mathrm{Ca}^{2+}, \mathrm{Mg}^{2+}, \mathrm{NH}_{4}^{+}, \mathrm{Cl}^{-}$and $\mathrm{SO}_{4}^{2-}$ from their initial concentrations in raw water. This showed that the mathematical model was able to predict the concentrations of cations and anions investigated in this study. The result revealed that the flow rate of water has effect on the treatment of cations and anions in raw water using ion-exchange resins. Thus, operating the resin beds at very high flow rate reduced its performance while at very low flow rate the residence time of wastewater on the bed increased with resultant increase in performance. Similarly, high superficial velocity reduced the amount of ion concentration removed by the resin in both beds. The total final concentrations of cations in the cation bed by the model were $0.0003156,0.0003452$ and $0.0036 \mathrm{~mol} / \mathrm{m}^{3}$ at $4.0,4.5$ and $6.5 \mathrm{~m} / \mathrm{min}$ respectively while that from the anion bed were $0.0002597,0.0002769$ and $0.00205 \mathrm{~mol} / \mathrm{m}^{3}$ at $4.0,4.5$ and 6.5 $\mathrm{m} / \mathrm{min}$ respectively. The predicted model results, when compared with the maximum allowable limit of total concentration of both cations and anions of a functional industrial company (Notore chemical), showed a maximum percentage deviation ranging from $2.00 \%$ to $3.53 \%$. This showed that the developed model has achieved its set objectives.
\end{abstract}

\section{Keywords}

Raw Water, Cation, Anion, Ion Exchange, Mathematical Modeling 


\section{Introduction}

Boilers are the heartbeat of thermal power plants which require a high purity water to operate in order to protect the internal installations against corrosion and fouling. When mineral salts, acids and bases are in water solution, they break down into ions with either positive or negative electrical charges. Ions with positive charges are called cations, while those with negative charges are called anions. These ions are reactive if allowed into a boiler, therefore detrimental to boiler tubes resulting in poor performance. To solve this problem, plastic beads called ion exchange resins have been developed to trap these unwanted ions from entering into the boiler using a process called Demineralization. The ion exchange resins have high affinity to either cations or anions [1]. The cation resins are subjected to high concentration of hydrogen, and the anion resins are subjected to a high concentration of hydroxide ions. These ions however, have relatively low electrical potential in raw water. Demineralization occurs when raw water containing cation such as calcium, magnesium or sodium (which all have a greater potentials than hydrogen) flows through a cation bed and makes contact with ion exchange resin (beads), and immediately upon contact, the stronger cations displaces more loosely held hydrogen ion and bonds themselves to the resins. Also, sulpates and nitrate, (all negatively charged ions) bond to anion resin beads, displacing hydroxide ion with low electrical potential and released it into water. The hydrogen ions $(\mathrm{H})$ from the cation bed combine with the hydroxide ions $(\mathrm{OH})$ from anion bed to form water. Failures normally occur in the performance of boilers over long period of continuous operation. Over the years, there exists accumulation of scale formation resulting from corrosion, pitting and film filings [2] [3]. These defects lead to poor heat transfer efficiency in boiler tubes and exchanger pipes, which increases cost of operation and may result in unscheduled shutdown. Chemical Industries like the Nigerian Fertilizer Company, which quality policy is committed to total customer satisfaction by consistently meeting and exceeding the expectations of her customers for providing quality nitrogenous fertilizers and allied products, on time and of competitive prices will be defeated [4]. This will lead to customer dissatisfaction, scarcity of fertilizers to farmers; lay off of workers and loss of profit. It is in consideration of the above facts that this research work is embarked upon. When raw water is fed from a raw water storage tank or directly from well into the carbon filter by the water treatment feed pumps; it flows through the top of the vessel and out through the bottom. The carbon filter is designed in such a way as to remove taste, odour, colour and chlorine from raw water [5] [6]. It consists of a vertical, cylindrical pressure tank with dishes heads containing a filter bed of granular activated carbon. When the carbon filter is in operation, water enters the top of the filter and is evenly distributed over the media bed. As it flows through the bed, turbidity is trapped at the top of the bed, while organics adsorbed on the carbon granules throughout the entire bed [7]. The filtered water 
from the carbon filter unit enters into the two bed demineralizer. Two-bed demineralizer consists of two separate vertical vessels, cylindrical pressure tanks with dishes heads containing a bed of cation resin in the first tank and anion resin in the second tank. As the filtered water flows through the service inlet valve of the cation resin beads, all the positively charged ions are removed from the filtered water. The dilute hydrochloric acid $(\mathrm{HCl})$ formed in this reaction is undesirable because of its corrosive nature and thus must be removed from the system by flowing it through the anion exchanger bed to reacts with the anion rein ( $\mathrm{ROH})$ to form a chlorine resin complex and water [8] [9]. This reaction takes place in the anion exchange vessel. Usually the cation exchanger must always be placed before the anion exchanger in order that the weak acid formed in the cation exchanger can flow through anion resin in the anion bed to form water. This process also helps to remove the deposition of calcium and magnesium sulphate from raw water. The water formed in the anion bed no doubt must contains some impurities; consequently, the water must flow through the mixed bed exchangers which provides a final polishing of the water before it passes to the demineralized water storage tank [10]. So far from works reviewed [11] [12] [13] [14], depicted that several type of resin had been developed and the adsorption capacity tested with several cations. Also, the results obtained in nearly all the works reviewed were subjected to mathematical model. However, virtually all the works reported were based on experimental results rather than real functional data obtained from industrial process effluent [10] [15] [16] [17]. Also, the anion removed from raw water was not investigated, which could be a serious threat to some process equipment such as boiler. It is in the objective of this research to use real industrial process data of anions and cations bed from a functional Fertilizer company in Nigeria to study the efficacy of resin capacity in removing cations and anions via the mathematical model developed using the principle of conservation of mass for the processes. The aim of this work is to study the ion exchange demineralization process of boiler feed water treatment through development of mathematical model that will predict optimal performance of the boiler feed water treatment plant. The specific objectives were to: develop the performance model of demineralization process, integrate the developed model numerically using the Runge-Kutta adopting operating data obtained from a functional industrial Fertilizer company in Nigeria, and validate the model predictions with plant data. Also, simulate functional parameters to predict optimum operating conditions for removal of contaminants (minerals) by the ion exchange facility.

\section{Development of Mathematical Model}

The model was developed by assuming a hypothetical system representing cation and anion bed as shown in Figure 1. Applying the principle of conservation of mass, the model describing the ion concentrations in the mixed bed effluent stream was developed as follows: 


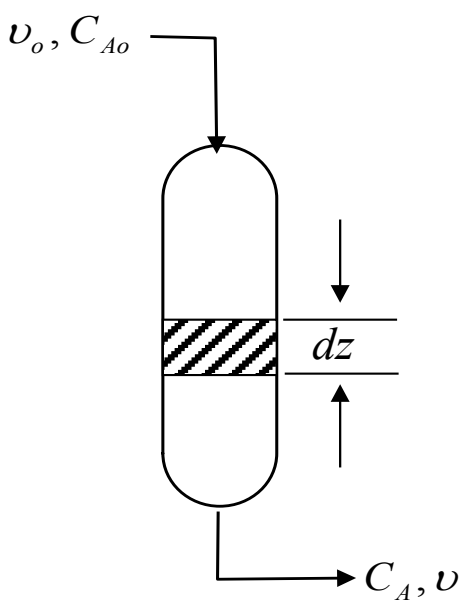

Figure 1. Schematic diagram of fixed bed ion exchange facility.

$$
A \mathrm{~d} z \frac{\partial C_{A}}{\partial t}=-\frac{\partial}{\partial z}\left(\bar{u} C_{A}+N_{A}\right) A \mathrm{~d} z+R_{A} A \mathrm{~d} z
$$

where $C_{A}=$ concentration of ion in the liquid phase $\left(\mathrm{mol} / \mathrm{m}^{3}\right), t=$ time $(\mathrm{min}), Z$ = bed height $(\mathrm{m}), A=$ bed cross-sectional area $\left(\mathrm{m}^{2}\right), \bar{u}=$ the average fluid flowing velocity in all directions $(\mathrm{m} / \mathrm{min}), N_{A}=$ molar flux of component $A$ in the mixture $\left(\mathrm{mol} / \mathrm{min} \cdot \mathrm{m}^{2}\right), R_{A}=$ rate of ion-exchange $\left(\mathrm{mol} / \mathrm{m}^{3} \cdot \mathrm{min}\right)$.

Dividing all through by $A \mathrm{~d} z$ yields

$$
\frac{\partial C_{A}}{\partial t}=-\frac{\partial}{\partial z}\left(\bar{u} C_{A}+N_{A}\right)+R_{A}
$$

Equation (2) is the dynamic model for the cylindrical column embedded with resin to remove ions in wastewater. This model incorporated flow due to diffusion and bulk flow. However, for cylindrical system,

$$
\bar{u}=u_{r}+u_{\theta}+u_{z}
$$

where $u_{r}=$ velocity in radial direction $(\mathrm{m} / \mathrm{min}) . u_{\theta}=$ velocity in axial direction $(\mathrm{m} / \mathrm{min}), u_{z}=$ velocity in the vertical direction $(\mathrm{m} / \mathrm{min})$. The molar diffusion flux of ion concentrations on the bed in the three direction is:

$$
N_{A}=-D_{e}\left(\frac{\partial C_{A}}{\partial r}+\frac{\partial C_{A}}{\partial \theta}+\frac{\partial C_{A}}{\partial z}\right)
$$

Substituting Equation (3) and (4) into Equation (2) and assuming that the effects of fluid flow along the radial and axial directions were negligible, we obtained the model:

$$
\begin{aligned}
& \frac{\partial C_{A}}{\partial t}=-\frac{\partial}{\partial z}\left[u_{z} C_{A}-D_{e}\left(\frac{\partial C_{A}}{\partial z}\right)\right]+R_{A} \\
& \frac{\partial C_{A}}{\partial t}=-\frac{\partial}{\partial z}\left(u_{z} C_{A}\right)+D_{e} \frac{\partial^{2} C_{A}}{\partial z^{2}}+R_{A}
\end{aligned}
$$

Equation (5) is the dynamic model for the fixed bed in the vertical direction. Assumed that the bed operates at steady state, Equation (5) is reduced to 


$$
\frac{\mathrm{d}}{\mathrm{d} z}\left(u_{z} C_{A}\right)=D_{e} \frac{\mathrm{d}^{2} C_{A}}{\mathrm{~d} z^{2}}+R_{A}
$$

Where $C_{A O}, C_{A}=$ initial and final concentration, $v_{o}, v=$ initial and final volumetric flow rate, $\mathrm{d} Z=$ differential bed height.

From [6], the rate of mass transfer through the film is related to the bulk concentration of the liquid by:

$$
D_{e} \frac{\mathrm{d} C_{A}}{\mathrm{~d} z}=K_{L}\left(C_{A o}-C_{A}\right)
$$

where: $K_{L}=$ mass transfer coefficient $(\mathrm{m} / \mathrm{s}), D_{e}=$ effective diffusion coefficient $\left(\mathrm{m}^{2} / \mathrm{s}\right)$.

Hence, for constant fluid velocity and substituting Equation (7) into Equation (6) yields

$$
\begin{gathered}
u_{z} \frac{\mathrm{d} C_{A}}{\mathrm{~d} z}=K_{L} \frac{\mathrm{d}}{\mathrm{d} z}\left(C_{A o}-C_{A}\right)+R_{A} \\
u_{z} \frac{\mathrm{d} C_{A}}{\mathrm{~d} z}=-K_{L} \frac{\mathrm{d} C_{A}}{\mathrm{~d} z}+R_{A} \\
\left(u_{z}+K_{L}\right) \frac{\mathrm{d} C_{A}}{\mathrm{~d} z}=R_{A}
\end{gathered}
$$

The mass transfer rate of ion exchange, $R_{A}$ in the resin phase has been expressed by [18] as:

$$
R_{A}=\frac{\mathrm{d} C_{s}}{\mathrm{~d} t}=k_{1} C_{A}\left(C_{s m}-C_{s}\right)-k_{2} C_{s}\left(C_{A o}-C_{A}\right)
$$

Hence, at equilibrium

$$
R_{A}=\frac{\mathrm{d} C_{s}}{\mathrm{~d} t}=k_{1}\left[C_{A}\left(C_{s m}-C_{s}\right)-\frac{1}{K_{d}} C_{s}\left(C_{A o}-C_{A}\right)\right]
$$

where: $C_{s}=$ Concentration of ion in the resin $\left(\mathrm{mol} / \mathrm{m}^{3}\right) . C_{A}=$ Concentration of ion in the liquid $\left(\mathrm{mol} / \mathrm{m}^{3}\right)$.

$C_{s m}=$ Maximum concentration of ion in the resin $\left(\mathrm{mol} / \mathrm{m}^{3}\right) . K_{d}=\frac{k_{1}}{k_{2}}=$ Equilibrium constant (dimensionless).

Since the amount of ion concentrations removed from raw water are being trapped by the resins, it followed that the rate of ion concentrations in the liquid phase was equivalent to the rate of ion concentration in the resin phase, thus:

$$
R_{A}=\frac{\mathrm{d} C_{S}}{\mathrm{~d} t}=-\frac{\mathrm{d} C_{A}}{\mathrm{~d} t}
$$

Hence, combining Equation (8), Equation (10) and Equation (11) yields:

$$
\therefore-\frac{\mathrm{d} C_{A}}{\mathrm{~d} z}=\left(\frac{k_{1}}{u_{z}+K_{L}}\right)\left[C_{A}\left(C_{S m}-C_{S}\right)-\frac{1}{K_{d}} C_{S}\left(C_{A O}-C_{A}\right)\right]
$$

Equation (12) represents the steady state model equation for the ion-exchange bed.

$K_{d}$ was obtained from an expression by [18] given as: 


$$
K_{d}=\frac{y_{A} / x_{A}}{\left[\left(1-y_{A}\right) /\left(1-x_{A}\right)\right]^{2}} \times \frac{C_{A o}}{C_{S m}}
$$

where $x_{A}$ and $y_{A}$ are ionic mole fractions in liquid and resin and they are expressed as:

$$
x_{A}=\frac{C_{A}}{C_{A o}} ; y_{A}=\frac{C_{S}}{C_{S m}}
$$

In practice, the desired values of the ionic mole fractions in the liquid and resin phases have to be specified [5]. In this work, the values used were $x_{A}=0.03$ and $y_{A}=0.9$. Also, the value of the mass transfer coefficient $K_{L}$ was obtained from the work of [6] as $1.92 \times 10^{-6} \mathrm{~m} / \mathrm{s}$.

\subsection{Residence Time, $\tau_{m}$}

The residence time, $\tau_{m}$ can be expressed as:

$$
\tau_{m}=\frac{\varepsilon_{r} V}{v_{o}}
$$

where $v_{o}=$ Volumetric flow rate $\left(\mathrm{m}^{3} / \mathrm{min}\right), \varepsilon_{r}=$ Bed voidage.

\subsection{Operating Parameters}

Table 1 depicts the cation and anion bed dimension and the mass transfer coefficient obtained from specified literatures and industrial plant data. Table 2 shows the inlet and outlet ion concentrations of the metallic and nonmetallic pollutants in the wastewater and treated water.

\subsection{Solution Technique}

The developed model (Equation (12)) was solved numerically using the $4^{\text {th }}$ order Runge-Kutta algorithm expressed by [5] as follows

$$
C_{A(i+1)}=C_{A(i)}+\left[k_{1}+2\left(k_{2}+k_{3}\right)+k_{4}\right] \frac{h}{6}
$$

where:

$$
\begin{gathered}
k_{1}=f\left(y_{i}, C_{A(i)}\right) \\
k_{2}=f\left(y_{i}+\frac{h}{2}, C_{A(i)}+\frac{h}{2} k_{1}\right) \\
k_{3}=f\left(y_{i}+\frac{h}{2}, C_{A(i)}+\frac{h}{2} k_{2}\right) \\
k_{4}=f\left(y_{i}+h, C_{A(i)}+h k_{3}\right) \\
i=1,2,3, \cdots, n .
\end{gathered}
$$

where $h=$ step size.

Using the following initial and boundary conditions. At $z=0, C_{A}=C_{A o}$; and at maximum exchangeable capacity: 
Table 1. Dimension of the bed.

\begin{tabular}{ccc}
\hline Parameter & Value & Reference \\
\hline Bed height $(\mathrm{m})$ & 5.0 & {$[4]$} \\
Bed radius $(\mathrm{m})$ & 0.6034 & {$[4]$} \\
Voidage (-) & 0.003 & {$[4]$} \\
Mass Transfer Coefficient $K_{L}(\mathrm{~m} / \mathrm{min})$ & $1.92 \times 10^{-6}$ & {$[6]$} \\
\hline
\end{tabular}

Table 2. Cation and anion concentrations $\left(\mathrm{mol} / \mathrm{m}^{3}\right)$.

\begin{tabular}{cccc}
\hline Parameter & Initial Value & Exit value & Reference \\
\hline $\mathrm{Na}^{+}$ & $0.5862(37.1 \mathrm{ppm})$ & $0.0002142(0.01356 \mathrm{ppm})$ & {$[4]$} \\
$\mathrm{Ca}^{2+}$ & $0.079(5.0 \mathrm{ppm})$ & $0.0000293(0.00185 \mathrm{ppm})$ & {$[4]$} \\
$\mathrm{Mg}^{2+}$ & $0.194(12.3 \mathrm{ppm})$ & $0.0000712(0.00451 \mathrm{ppm})$ & {$[4]$} \\
$\mathrm{NH}_{4}^{+}$ & $0.0221(1.4 \mathrm{ppm})$ & $0.0000081(0.00051 \mathrm{ppm})$ & {$[4]$} \\
$\mathrm{Cl}^{-}$ & $0.2228(14.1 \mathrm{ppm})$ & $0.0000813(0.00514 \mathrm{ppm})$ & {$[4]$} \\
$\mathrm{SO}_{4}^{2-}$ & $0.4930(31.2 \mathrm{ppm})$ & $0.0001856(0.01175 \mathrm{ppm})$ & {$[4]$} \\
\hline
\end{tabular}

$\mathrm{ppm}=0.0158 \mathrm{~mol} / \mathrm{m}^{3}$.

$$
z>0, C_{A}=C_{(z)}
$$

\section{Results and Discussion}

Table 3 shows the comparison between model predictions (Equation (12)) with industrial plant data for the cation and anion concentrations showing a percentage deviation ranging from a minimum of $2.0 \%$ to a maximum of $3.59 \%$ indicating reasonable agreement at plant operating superficial velocity of $4.0 \mathrm{~m} / \mathrm{min}$.

\section{Results Simulation}

The model results for cations and anions were simulated and the effects of flow rates and fluid velocity on resin capacity were also studied.

The profile in Figure 2 shows that calcium ion concentration flowing at velocity of $4.0 \mathrm{~m} / \mathrm{min}$ decreased from initial concentration of $0.079 \mathrm{~mol} / \mathrm{m}^{3}$ to a final concentration of $0.0000283 \mathrm{~mol} / \mathrm{m}^{3}$ after been in contact with the resin. This showed that $0.07897 \mathrm{~mol} / \mathrm{m}^{3}$ of calcium ion concentration had been removed by the resin in the cation bed indicating that about $99.96 \%$ of calcium ion were removed by the resin. However, the maximum concentration of calcium ion in the effluent water from the plant cation bed was $0.0000293 \mathrm{~mol} / \mathrm{m}^{3}$ which is greater than the final concentration as obtained from the model equation with deviation of $3.53 \%$.

The profile in Figure 3 shows that sodium ion concentration flowing with velocity of $4.0 \mathrm{~m} / \mathrm{min}$ decreased along the height of the cation bed, from initial concentration of $0.5862 \mathrm{~mol} / \mathrm{m}^{3}$ to final concentration of $0.00021 \mathrm{~mol} / \mathrm{m}^{3}$ indicating that $0.58599 \mathrm{~mol} / \mathrm{m}^{3}$ of sodium ion concentration had been removed by the resin in the cation bed accounting for about $99.96 \%$ removal with a deviation of $2 \%$. 
Table 3. Comparison of model predictions with plant data at superficial velocity $=4.0$ $\mathrm{m} / \mathrm{min}$.

\begin{tabular}{cccc}
\hline Component & $\begin{array}{c}\text { Model Prediction } \\
\left(\mathrm{mol} / \mathrm{m}^{3}\right)\end{array}$ & Plant Data $\left(\mathrm{mol} / \mathrm{m}^{3}\right)$ & \% Deviation \\
\hline Cation Bed & 0.00021000 & 0.0002142 & 2.00 \\
$\mathrm{Na}^{+}$ & 0.00002830 & 0.0000293 & 3.53 \\
$\mathrm{Ca}^{2+}$ & 0.00006940 & 0.0000712 & 2.59 \\
$\mathrm{Mg}^{2+}$ & 0.00000791 & 0.00000081 & 2.40 \\
$\mathrm{NH}_{4}^{+}$ & & & \\
$\mathrm{Anion} \mathrm{Bed}^{-}$ & 0.0000797 & 0.0000813 & 2.00 \\
$\mathrm{Cl}^{-}$ & 0.0001800 & 0.0001856 & 3.11 \\
$\mathrm{SO}_{4}^{2-}$ & & & \\
\hline
\end{tabular}

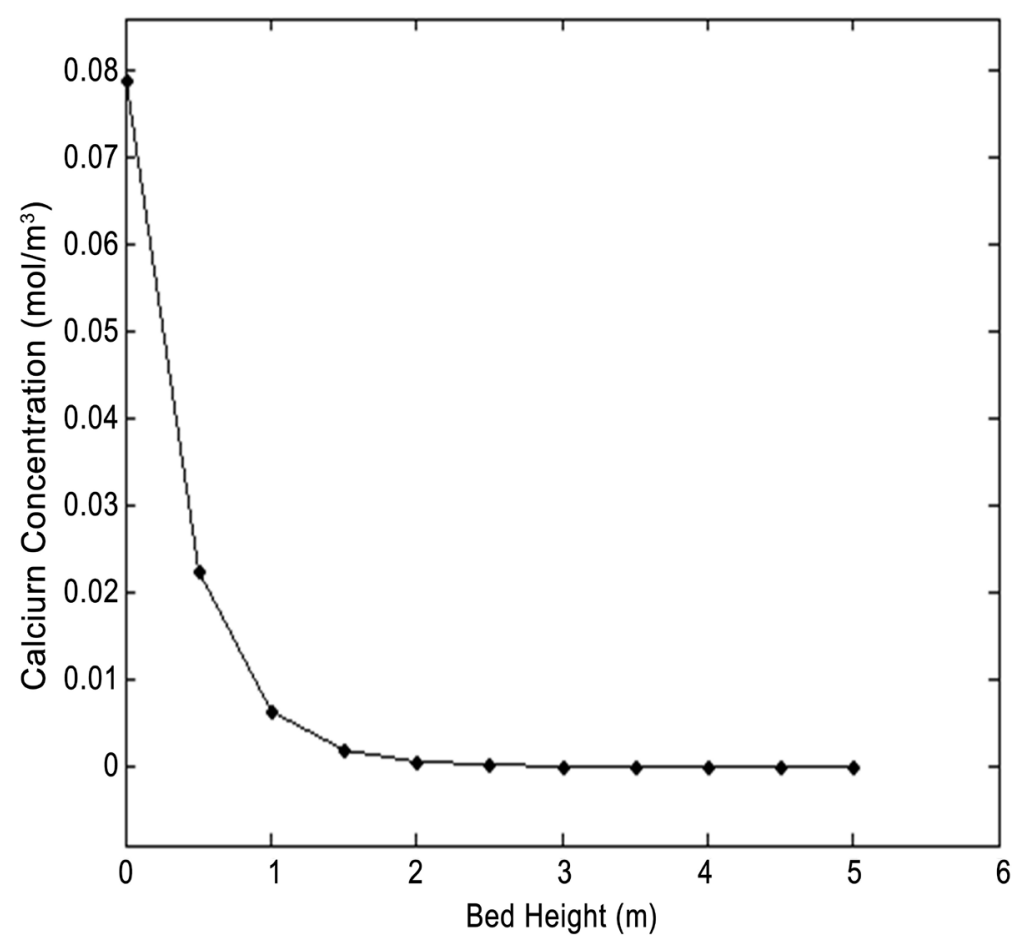

Figure 2. Calcium ion concentration removal from the cation bed.

The magnesium ion concentration in Figure 4, depicts that ion concentration of magnesium in waste water flowing at velocity of $4.0 \mathrm{~m} / \mathrm{min}$ decreased along the height of the cation bed, from an initial concentration of $0.194 \mathrm{~mol} / \mathrm{m}^{3}$ to $0.0000694 \mathrm{~mol} / \mathrm{m}^{3}$ accounting for $0.19393 \mathrm{~mol} / \mathrm{m}^{3}$ of magnesium ion concentration removal. However, the comparison of model predictions $\left(0.0000694 \mathrm{~mol} / \mathrm{m}^{3}\right)$ with plant data $\left(0.0000718 \mathrm{~mol} / \mathrm{m}^{3}\right)$ for magnesium ion removal in the effluent water showed a deviation of $2.59 \%$.

Similarly, Figure 5 showed that ion concentration of potassium in waste water flowing at velocity of $4.0 \mathrm{~m} / \mathrm{min}$ decreased along the height of the cation bed, from an initial concentration of $0.0221 \mathrm{~mol} / \mathrm{m}^{3}$ to an $0.00000791 \mathrm{~mol} / \mathrm{m}^{3}$ with 


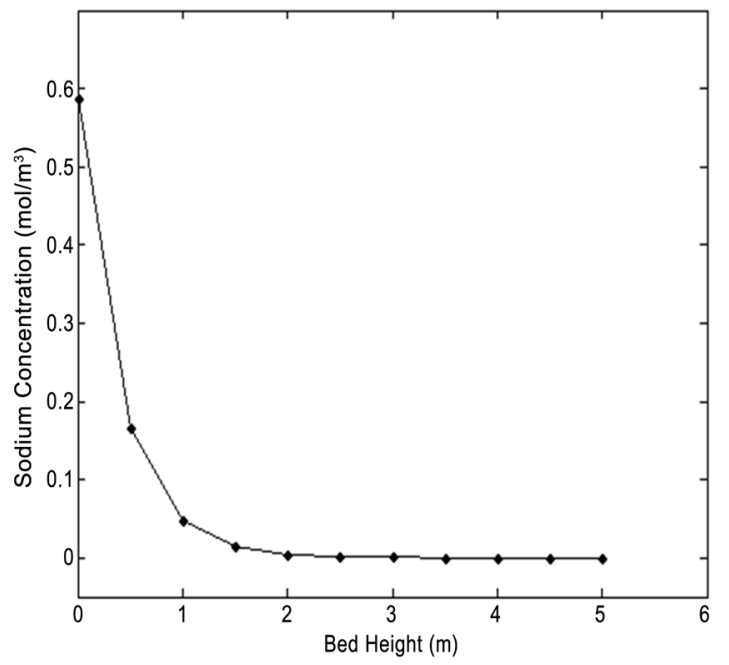

Figure 3. Sodium ion concentration removal from the cation bed.

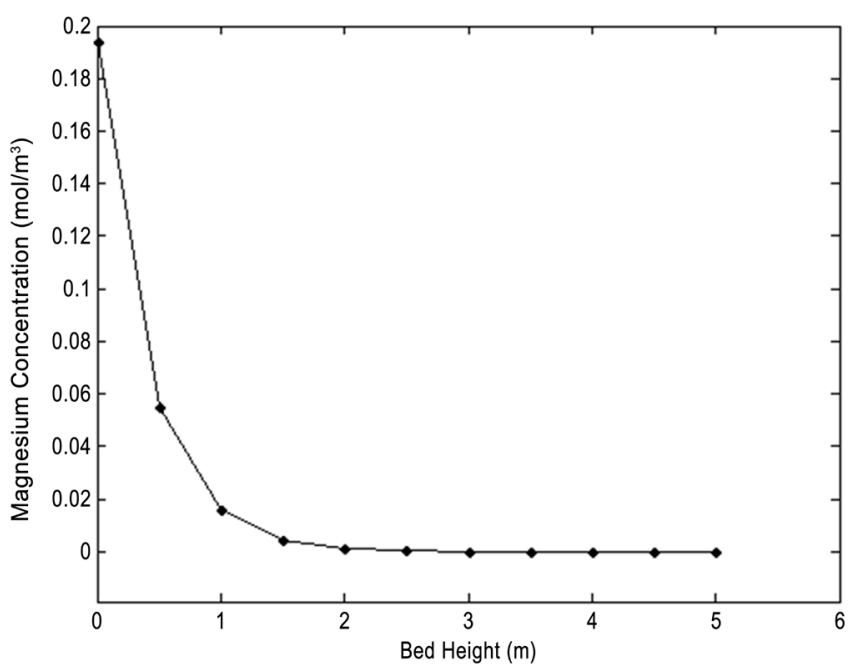

Figure 4. Magnesium ion concentration removal from the cation bed.

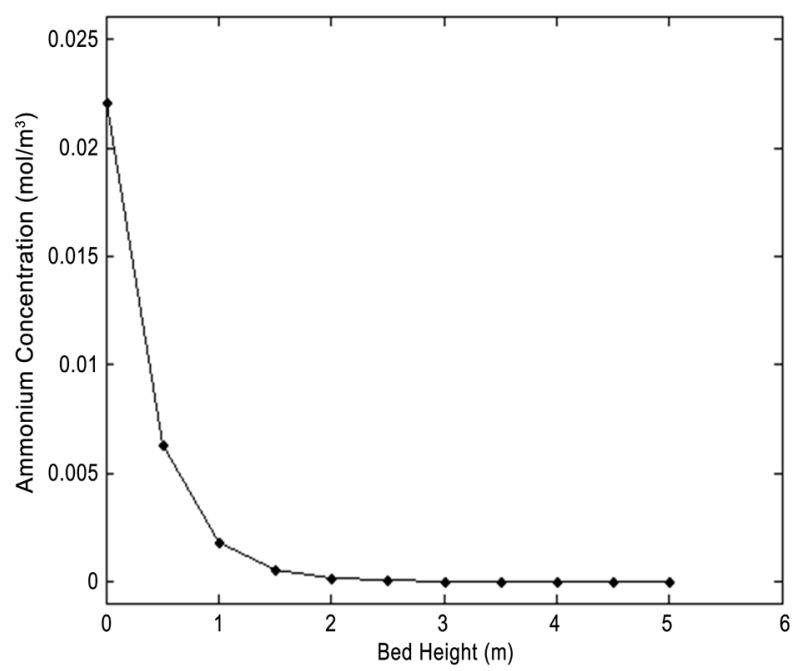

Figure 5. Ammonium ion concentration removal from the cation bed. 
$0.022092 \mathrm{~mol} / \mathrm{m}^{3}$ of ammonium ion concentration been removed by the resin. The comparison of model predictions $\left(0.0000081 \mathrm{~mol} / \mathrm{m}^{3}\right)$ showed a deviation of $2.40 \%$.

Figure 6 shows the profiles of the concentration of sodium, Calcium, Magnesium and ammonium ions at the exit of the cation bed was less than that of sodium ion, which could be attributed to higher initial concentration of sodium ion in the raw water flowing into the cation bed. The comparison of the ion concentrations removed by the resins showed that the amount of ion concentrations remaining at the effluent of the bed depended on the initial concentrations of the metal ions in the inflow raw water. Also, the ion exchange capacity in the resin was also an important factor that affects the removal of the ion concentrations from industrial wastewater. In this study, a uniform maximum ion exchange capacity was used $\left(0.8137 \mathrm{~mol} / \mathrm{m}^{3}\right)$. However, the level of ion concentrations in the exit stream from the cation bed for the four metal ions investigated showed that the efficacy of the exchange capacity in the resin was suitable as predicted by the model developed.

The chloride ion concentration in effluent water from the cation bed flowing into the anion bed at velocity of $4.0 \mathrm{~m} / \mathrm{min}$ as presented in Figure 7 showed that the ion concentration decreased as the height of bed increased (from initial concentration of 0.2228 to exit concentration of $0.0000797 \mathrm{~mol} / \mathrm{m}^{3}$ ) with $0.22272 \mathrm{~mol} / \mathrm{m}^{3}$ of the chloride ion concentration removed by the resin in the anion bed before flowing into the mixed bed. The comparison of model predictions $\left(0.0000797 \mathrm{~mol} / \mathrm{m}^{3}\right)$ with plant data $\left(0.0000831 \mathrm{~mol} / \mathrm{m}^{3}\right)$ for chloride ion removal showed a deviation of $2.00 \%$.

Similarly, sulfate ion concentration reduction is presented in Figure 8 indicating that as the bed height increased the ion concentration in effluent water

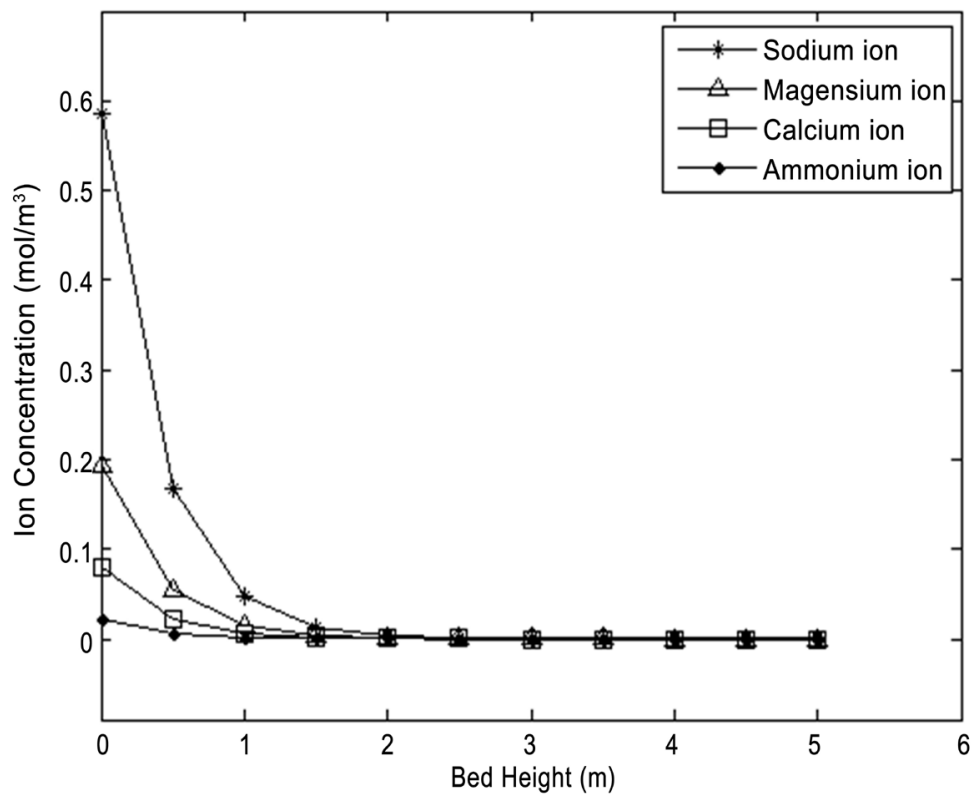

Figure 6. Comparison of ion concentration removal in cation bed. 


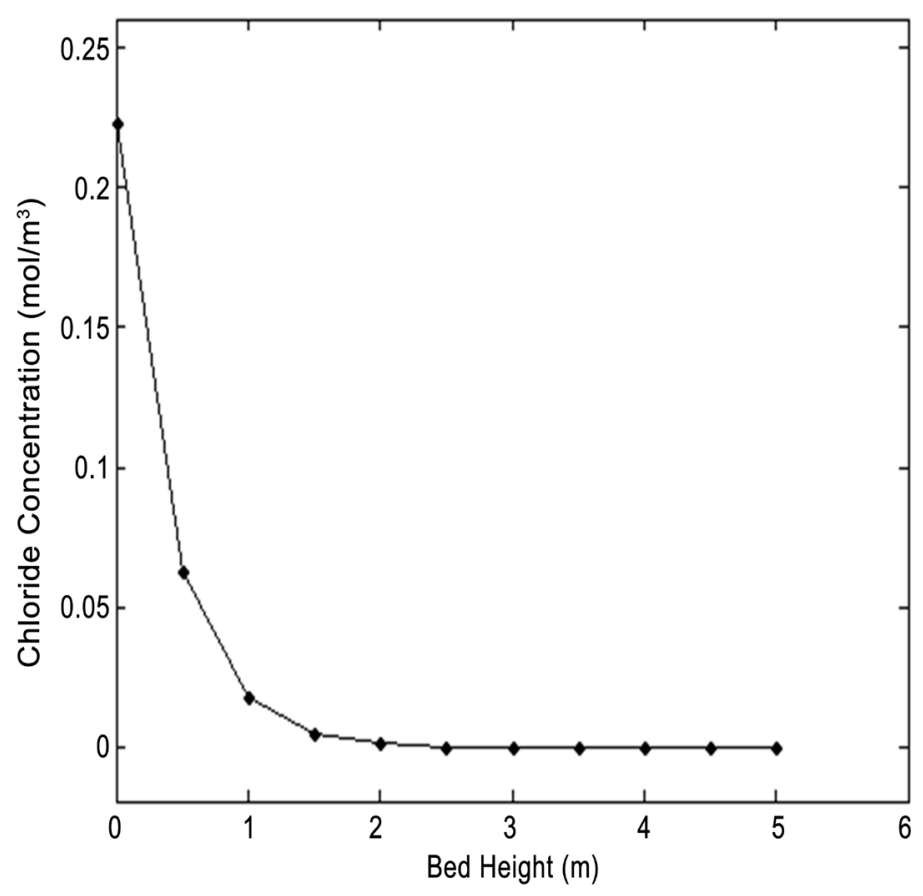

Figure 7. Chloride ion concentration removal from the anion bed.

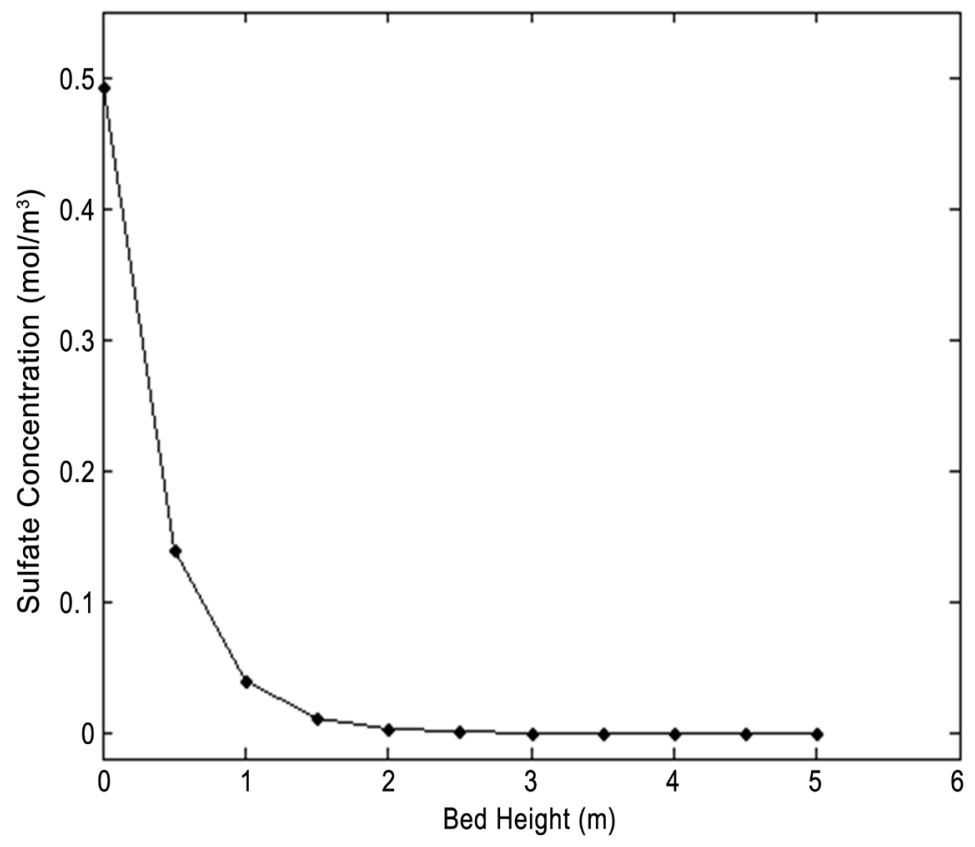

Figure 8. Sulfate ion concentration removal from the anion bed.

flowing into the anion bed at velocity of $4.0 \mathrm{~m} / \mathrm{min}$ decreased (from initial concentration of 0.4930 to exit concentration of $0.00018 \mathrm{~mol} / \mathrm{m}^{3}$ ), with $0.49282 \mathrm{~mol} / \mathrm{m}^{3}$ of the sulfate ion concentration removed by the resin in the anion bed before flowing into the mixed bed. The comparison of model prediction $\left(0.000018 \mathrm{~mol} / \mathrm{m}^{3}\right)$ with plant data $\left(0.00001856 \mathrm{~mol} / \mathrm{m}^{3}\right)$ for sulfate ion removal showed a deviation of $3.11 \%$. 
Figure 9 reveals that the amount of anion concentration left in the effluent water of the anion bed was dependent on the initial concentration of the anion in the inflow raw water and perhaps, some other factors such as the ion exchange capacity in the resin. In this study, the level of ion concentrations in the exit stream from the anion bed for the two anions investigated showed the effectiveness of the resin in the removal of anions.

The effect of fluid velocity as a factor that could improve or mar the removal of chloride ion was investigated as shown in Figure 10. The profiles showed that increasing the water velocity resulted in the reduction of the chloride ion concentration.

Figure 11 shows the effect of inlet water velocity on the removal of sulfate ion by the resin. It showed that varying the inlet velocity of raw water (4.0 to $6.0 \mathrm{~m} / \mathrm{min}$ ) resulted in decreased in the amount of sulfate ion concentration. This is as a result of longer residence time between the pollutant and the water. The longer the contact time, the higher the rate of removal of contaminants. Hence, at the lowest velocity of $4.5 \mathrm{~m} / \mathrm{min}$, highest level of contaminants removal was achieved.

Like the anion bed, the effect of raw water inlet velocity in the cation bed on the removal of sodium ion by the resin as shown in Figure 12 showed that increase in velocity of raw water (from 4.0 to $6.5 \mathrm{~m} / \mathrm{min}$ ), decreases the amount of sodium ion removed by the cation resin. However, the investigated water flowing velocity returns an acceptable limit of sodium ion concentration in the effluent. This is an indication that at certain higher velocities, the performance of cation resin could be ineffective such that sodium ion concentration in the effluent will be above the acceptable limit.

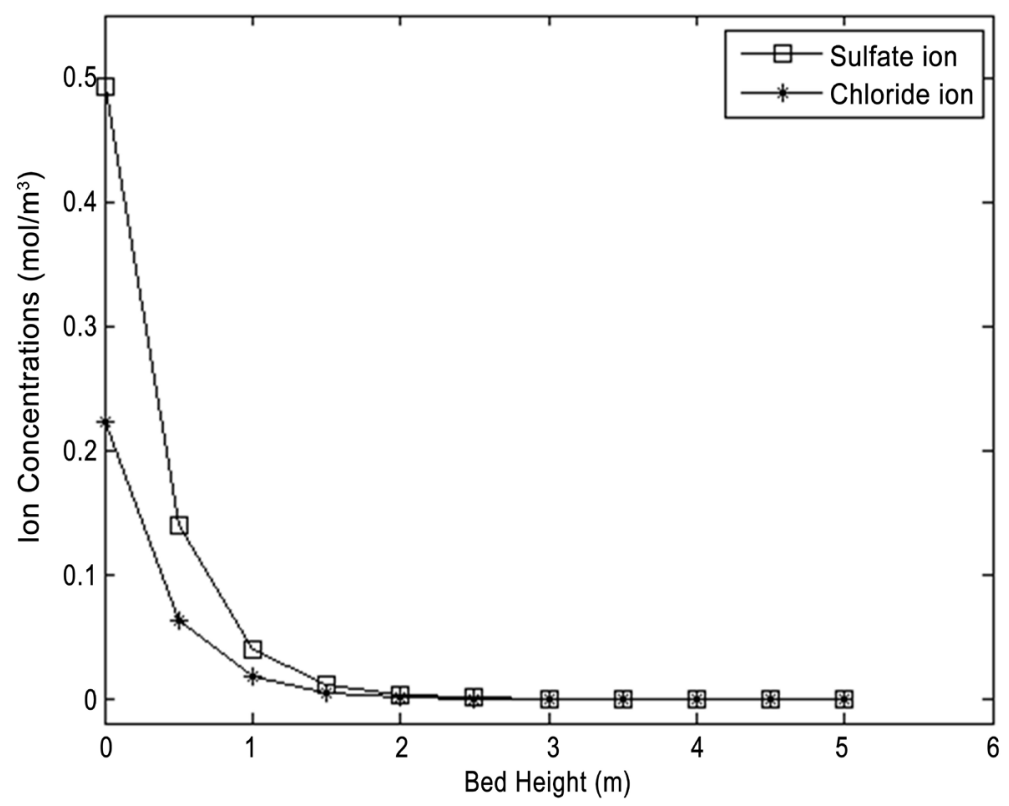

Figure 9. Comparison of sulphate and chloride ion concentration removal in the anion bed. 


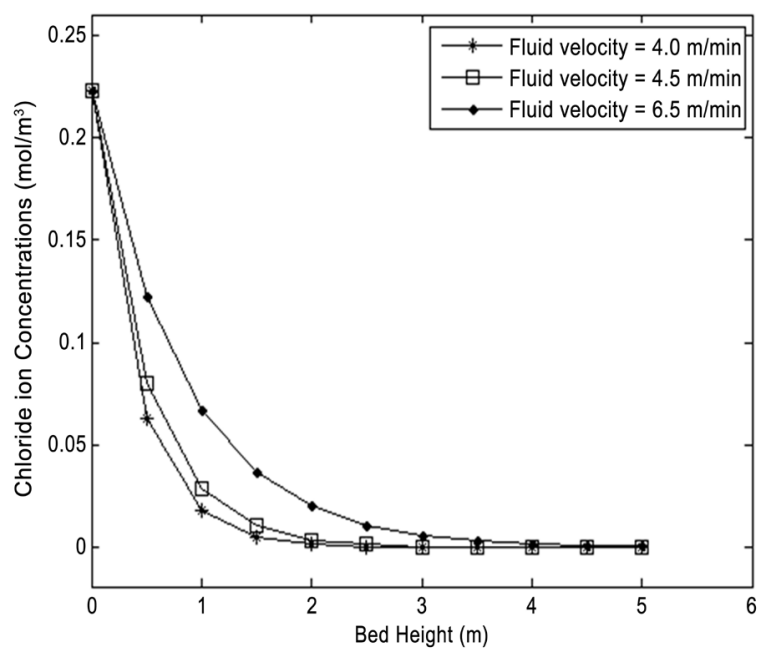

Figure 10. Effect of fluid velocity on chloride ion removal.

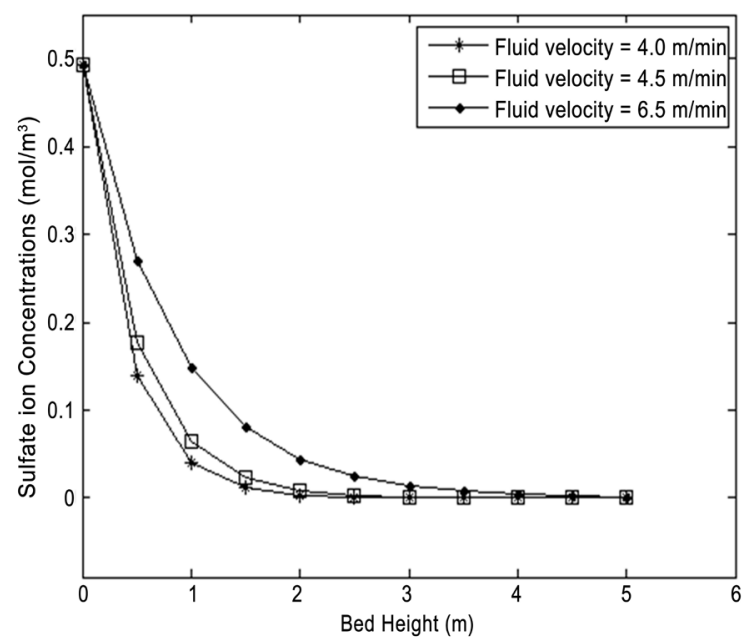

Figure 11. Effect of fluid velocity on sulfate ion removal.

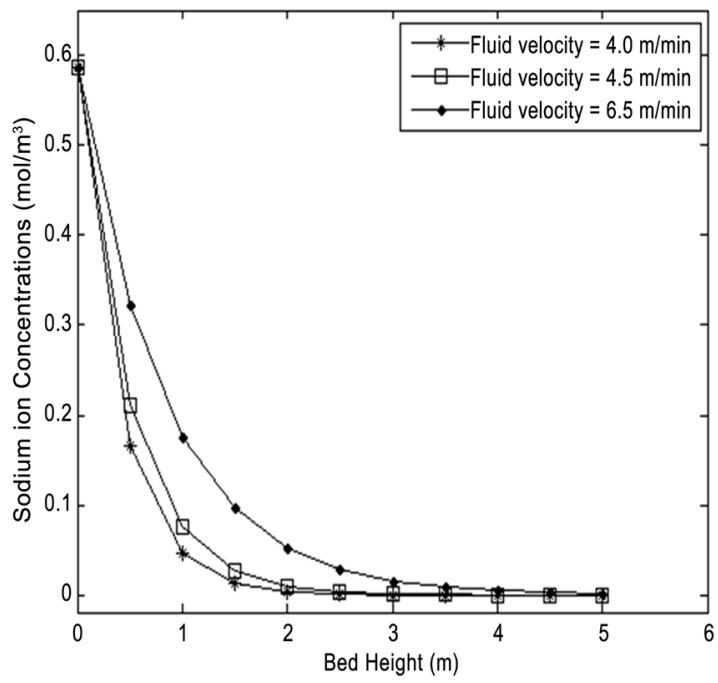

Figure 12. Sodium ion concentration versus bed height upon the influence of fluid velocity. 
Figure 13 shows the effect of water inlet velocity in the cation bed for the removal of ammonium ion by the cation resin. The profiles also revealed that increase in raw water flowing inlet velocity decreased the amount of ammonium ion concentration in the cation resin.

Figure 14 showed that increase in water inlet velocity in the anion bed (from 4.0 to $6.5 \mathrm{~m} / \mathrm{min}$ ) resulted in decrease in the amount of calcium ion concentration removed by the cation resin.

The effect of raw water inlet velocity on the removal of magnesium ion as shown in Figure 15 showed that increase in raw water inlet velocity (from 4.0 to

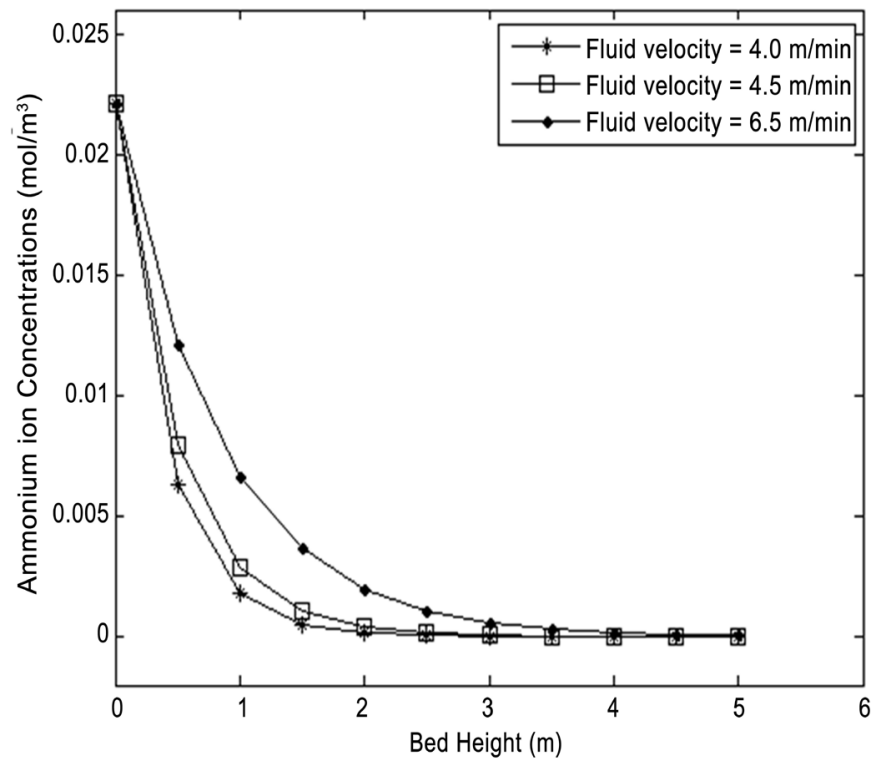

Figure 13. Ammonium ion concentration versus bed height upon the influence of fluid velocity.

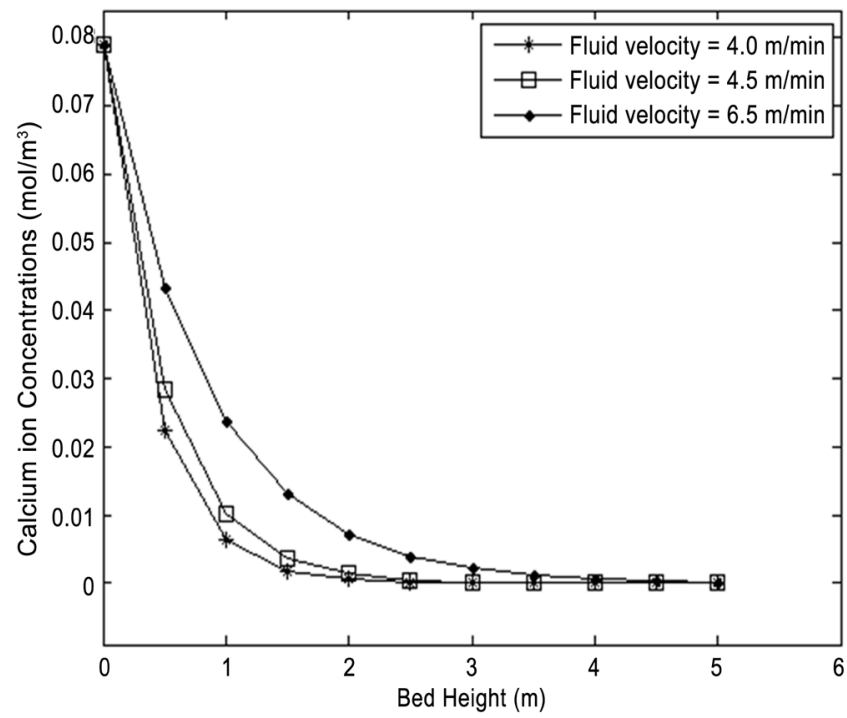

Figure 14. Calcium ion concentration versus bed height upon the influence of fluid velocity. 


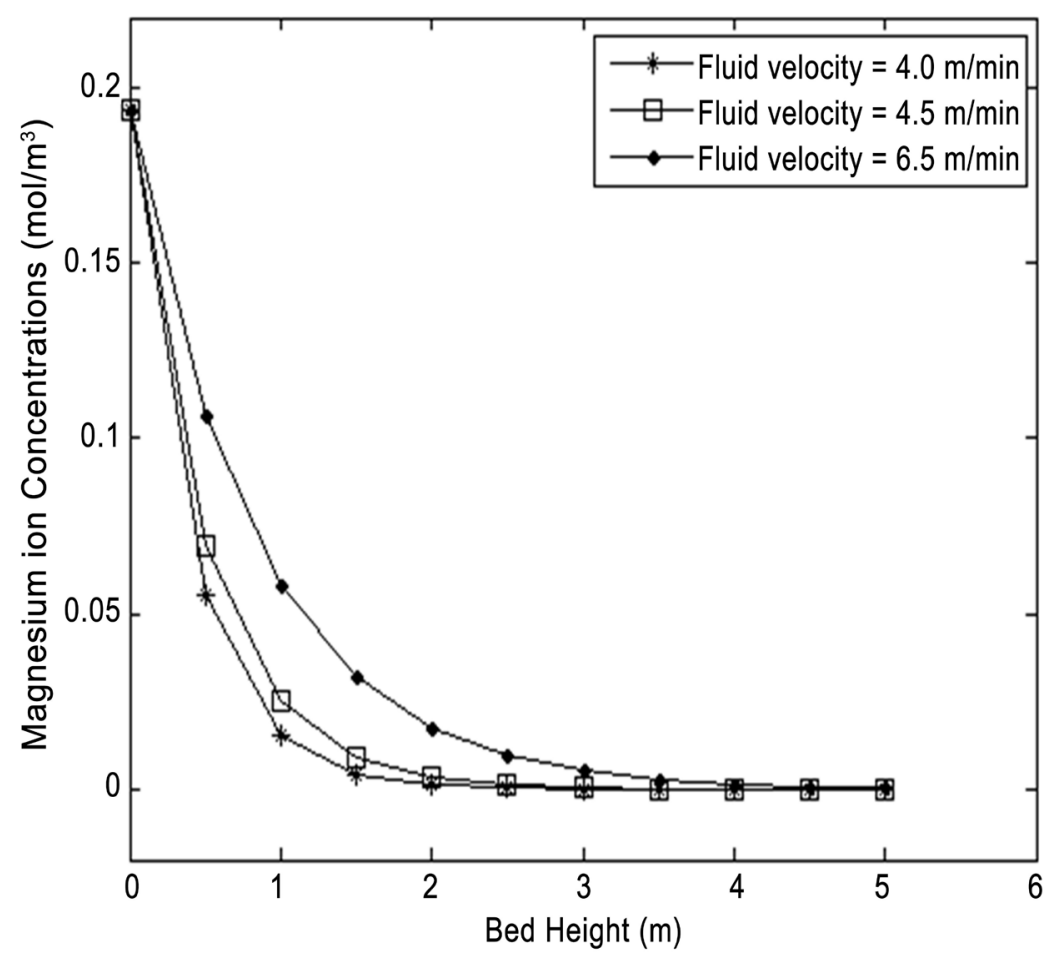

Figure 15. Magnesium ion concentration versus bed height upon the influence of fluid velocity.

$6.5 \mathrm{~m} / \mathrm{min}$ ), For sodium, ammonium and calcium ions resulted to decrease in the amount of ions along the bed height.

The effect of flow rate on the residence time of cations removal was investigated as shown in Figure 16. Increase in volumetric flow rate of raw water showed that the residence time of cation bed decreased with increase in the bed height. At low flow rate, the removal of cation concentration was very effective, because the raw water had sufficient contact time on the resin. But when the flow rate of water became high, the resin performance reduced. Thus, at very low and high volumetric flow rates, the plant productivity could be affected due to increased residence time or high level of ion concentrations in process water.

Similarly, in the cation bed, increasing the flow rate of water decreased the residence time. However, the residence time of contaminants increased with the resins increased in bed height as shown in Figure 17.

\section{Conclusion}

A model for an industrial ion exchange facility for demineralization of boiler feed water has been developed using the principle of conservation of mass. The model developed was integrated numerically using Runge-Kuttaalgorithm imbedded in MATLAB computer programming software. Results obtained were compared with industrial plant data and it agreed reasonably well with a percentage deviation ranging from $2.0 \%$ to $3.53 \%$ in the cation bed and $2.0 \%$ to $3.11 \%$ in the anion bed respectively, indicating that the developed model was adequate. 


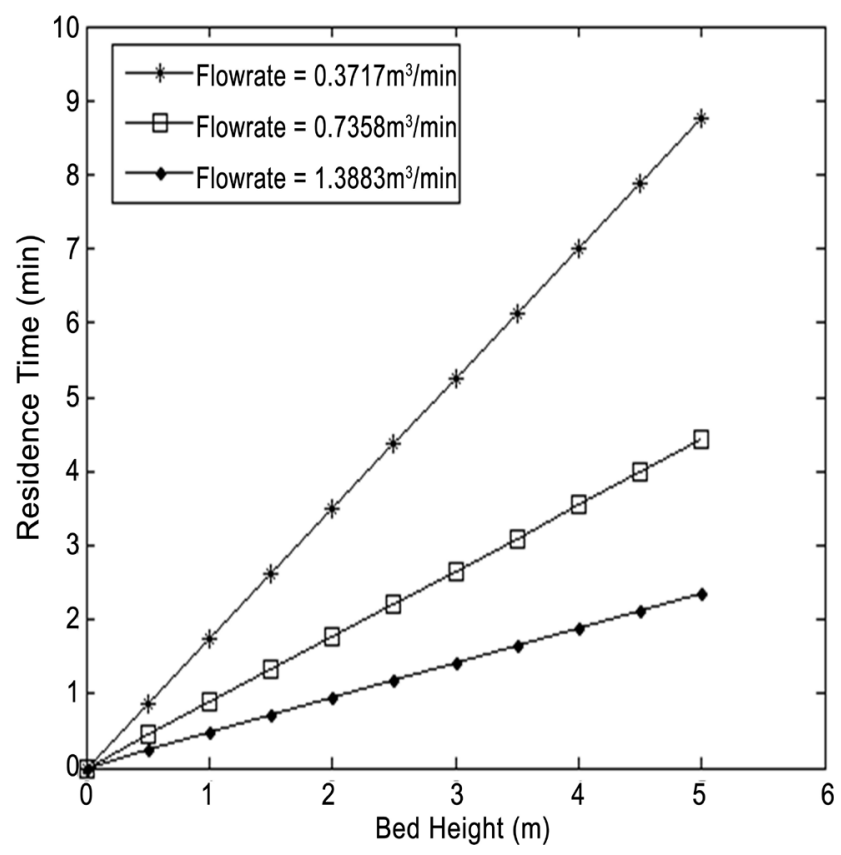

Figure 16. Effect of fluid flowrate on residence time of cations removal in cation bed.

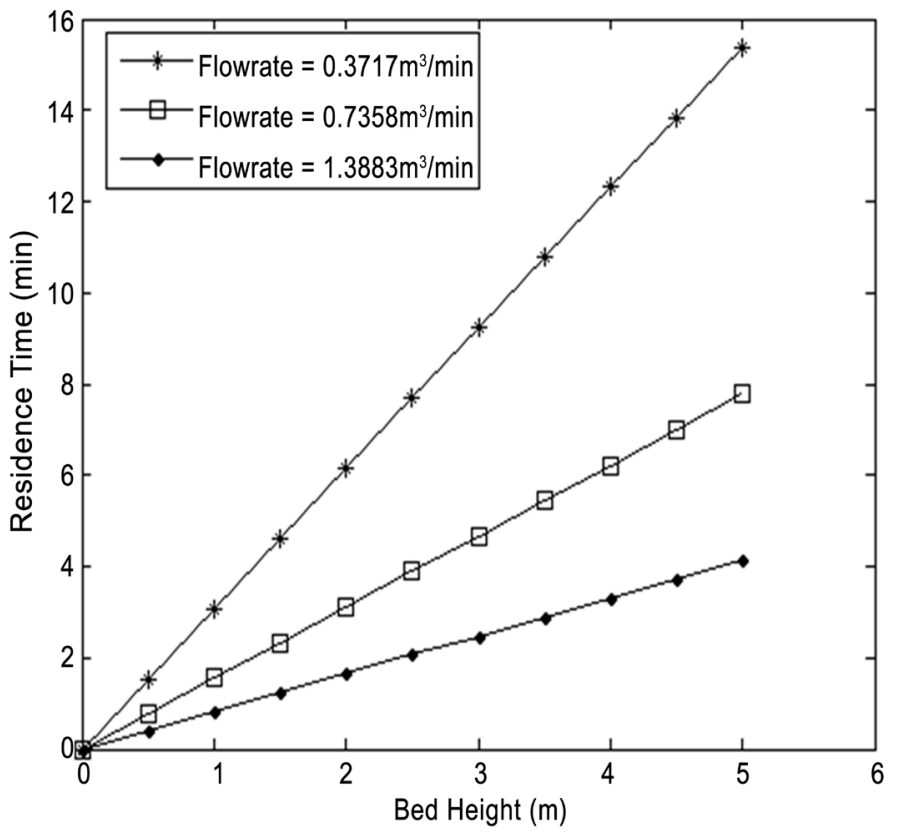

Figure 17. Effect of fluid flowrate on residence time of anion removal in anion bed.

Simulation was performed on functional parameters to predict optional variables for best performance of the ion exchange facility.

\section{Conflicts of Interest}

The author declares no conflicts of interest regarding the publication of this paper. 


\section{References}

[1] Corne, D. and Nalini, S.P. (2015) Demineralised Water Production Planning. Eskom. Johannesburg, 1-15.

[2] Aluyor, E.O. and Oboh, I.O. (2013) A Comparative Study of Zinc (II) Ions Removal by a Locally Produced Granular Activated Carbon. Covenant Journal of Physical and Life Sciences, 1, 14-18.

[3] Kenny, S. and Pope, D. (2000) Basic Water Treatment of Steam Boilers. Chemco Water Technology, Vancouver, 1-8.

[4] Notore Chemical Company (2012) Utilities/Off Sites Operating Manual. Onne, VI-26.

[5] Chapra, S.C. and Canale, R.P. (2010) Numerical Methods for Engineers. 6th Edition, McGraw-Hill, New York, 733-734.

[6] Menoud, P., Cavin, L. and Renken, A. (1998) Modelling of Heavy Metals Adsorption to a Chelating Resin in a Fluidized Bed Reactor. Chemical Engineering and Processing: Process Intensification, 37, 89-101. https://doi.org/10.1016/S0255-2701(97)00042-1

[7] Naja, G. and Volesky, B. (2006) Multi-Metal Biosorption in a Fixed-Bed Flow through Column. Chemical Engineering and Processing. Process Intensification, 281, 194-201. https://doi.org/10.1016/j.colsurfa.2006.02.040

[8] LA Water Treatment Corporation (1985) Water Treatment Study. National Fertilizer Company of Nigerian Operating Manual, 192-200.

[9] Nalco Chemical Company (1998) Ion Exchange Process. Naperville, 1-7.

[10] Nawaz, Z., Khan, J.R., Saleemi, A.R. and Shah, F. (2009) Mathematical Modelling for Magnetite (Crude) Removal from Primary Heat Transfer Loop by Ion-Exchange Resins. Bulletin of the Chemical Society of Ethiopia, 23, 129-133. https://doi.org/10.4314/bcse.v23i1.21310

[11] Kispotta, N., Choudhary, G., Sidar, D., Sen, P.K. and Bohidar, S.K. (2014) Common Boiler Feed Water Treatment in the Industry. International Journal of Innovative Research in Science and Technology, 1, 59-62.

[12] Leybros, A., Roubaud, A., Guichardon, P. and Boutin, O. (2012) Supercritical Water Oxidation of Ion Exchange Resins in a Stirred Reactor: Numerical Modelling. Chemical Engineering Science, 69, 170-180. https://doi.org/10.1016/j.ces.2011.10.016

[13] Behamidi, S., Larif, M., Ould-sidi, O., Eddine, K.J., Elhannouni, E. and Elmidaoui, A. (2014) Demineralization of Boiler Feed Water for the Thermal Power Stations: Study of Mineral and Oerganic Fouling of Reverse Osmosis Membranes. International Journal of Advanced Research in Computer Science and Software Engineering, 4, 86-91.

[14] Hani, H.A., El-Sayeda, M.M.H., Mostafab, A.A., El-Defrawya, N.M. and Soroura, M.H. (2012) Removal of Cr (III) in Batch and Pilot Scale Dynamic Systems Using Zeolite NaA Prepared from Egyptian Kaolin. International Journal of Chemical and Environmental Engineering, 3, 158-166.

[15] Nikkhah, K. (2003) Dynamic Modeling for Design of Ion Exchange Systems. Conference of the Joint Annual Meeting, Vancouver, August 2003, 1-12.

[16] Pambudi, K., Nurcahyo, W., Dhaema, K.A. and Tantrawan, W. (2012) Recirculation Process of Demineralization Water Treatment Plant to Reduce Conductivity Level of Water. Sixteenth International Water Technology Conference (IWTC), Istanbul, 
$1-8$

[17] Whitehead, K. (2014) Water Treatment Plant: The demineralization Process. Proceedings of the 2 nd Eskom System Dynamics Conference, Midrand, 12 November 2014, 88-102.

[18] Richardson, J.F., Harker, J.H. and Backhurst, J.R. (2002) Coulson and Richardson's Chemical Engineering: Particle Technology and Separation Process, Vol. 2, 5th Edition, Elsevier, New Delhi. 